\title{
KOLIČINE GORIVA I ZALIHE UGLJIKA U ŠUMSKOJ PROSTIRCI SASTOJINA ALEPSKOG BORA NA OTOKU MLJETU
}

\section{FOREST FLOOR FUEL LOADS AND CARBON STOCKS IN ALEPPO PINE FORESTS ON ISLAND OF MLJET}

\author{
Nera BAKŠIĆ, Darko BAKŠIĆ
}

\begin{abstract}
Sažetak
Sa stajališta šumskih požara, šumska prostirka se promatra kao potencijalno gorivo, no njena uloga i značaj u izmjeni tvari i energije, a poglavito ugljika u kontekstu aktualnih globalnih klimatskih promjena su veliki. Zbog toga se informacije o šumskoj prostirci tradicionalno koriste u modelima za procjenu opasnosti od šumskih požara te modelima za predikciju ponašanja i širenja šumskih požara, a u novije vrijeme i za procjenu emisija ugljika i drugih plinova te kvantificiranje zaliha ugljika. Glavni ciljevi ovog rada su: određivanje debljine, gustoće i količine pothorizonata šumske prostirke uz pripadajuće zalihe ugljika u sastojinama alepskog bora te izrada regresijskih modela debljine i količine šumske prostirke te debljine i zalihe ugljika, po pothorizontima i ukupno. Uzorkovanje šumske prostirke obavljeno je na području NP Mljet, u sastojinama alepskog bora, po debljinskim razredima: 0-50 $\mathrm{cm}, 100-150 \mathrm{~cm}$ i 200-250 cm opsega. Uzorkovanje je obavljeno po pothorizontima, a količine i udio organskog ugljika određene su za svaki pothorizont zasebno. Iz dobivenih rezultata vidljivo je da sastojine alepskog bora vežu značajne količine ugljika u svojoj prostirci, no uvjeti i zakonitosti nisu još dovoljno proučeni. U prilog tomu govore značajno veće debljine i količine šumske prostirke u sastojinama alepskog bora od onih do sada poznatih, pa je tako ispod stabala opsega $200-250 \mathrm{~cm}$ utvrđena srednja debljina prostirke od 9,0 cm i procijenjena količina od 94,3 $\mathrm{Mg} \mathrm{ha}^{-1}$ sa zalihom ugljika od $37 \mathrm{Mg} \mathrm{C} \mathrm{ha-1}^{-1}$. Regresijskom analizom utvrđena je statistički značajna veza debljina šumske prostirke $s$ količinama prostirke i zalihama ugljika, te su dani regresijski modeli za OL pothorizont, zatim $\mathrm{za} \mathrm{OF}_{1}, \mathrm{OF}_{2} \mathrm{i} \mathrm{OH}$ zajedno, kao i za ukupnu prostirku. Rezultati ovog istraživanja imaju praktičnu vrijednost $\mathrm{u}$ jednostavnijem kvantificiranju količina goriva i zaliha ugljika u šumskoj prostirci sastojina alepskog bora, koje se potom mogu koristiti u navedenim modelima. Inventarizacija šumskih goriva predstavlja osnovu za parametrizaciju i operativnu primjenu navedenih modela u Hrvatskoj.
\end{abstract}

KLJUČNE RIJEČl: alepski bor, šumska prostirka, količine goriva, zalihe ugljika

\section{UVOD}

\section{INTRODUCTION}

Šumska prostirka (engl. forest floor) predstavlja sveukupni organski materijal, koji se bez obzira na stupanj razgradnje nalazi na površini mineralnog dijela tla. Prema stupnju razgradnje najčešće se razlučuju tri pothorizonta ili sloja šum- ske prostirke, koji se označavaju kao OL, OF i OH ${ }^{1}$ (Zanella i dr., 2011). U šumskoj prostirci akumulirana je velika količina hraniva. Ona značajno utječe na fizička i kemijska svojstva tla te na pedogenetske procese. Biološki gledano, šumska prostirka predstavlja jednu od najvažnijih karika razmjene tvari između šume, tla i atmosfere (Martinović, 2003).

${ }^{1}$ Navedeni podhorizonti prema FAO priručniku (2006) označavaju se kao Oi, Oe i Oa, zatim još kao Ol, Of, Oh, a u literaturi vezanoj uz šumske požare i kao L, F i H. Nera Bakšić, dipl. ing. šum., Izv. prof. dr. sc. darko Bakšić, dbaksic@sumfak.hr, Sumarski fakultet Sveučilišta u Zagrebu, Svetošimunska c. 25 
Kombinacija dugotrajnih sušnih razdoblja i visokih temperatura tipičnih za mediteransku klimu pretvara šumsku prostirku iz potencijalnog u raspoloživo šumsko gorivo, povećavajući rizik od ekstremnih šumskih požara. Najvažnija pojedinačna značajka koja kontrolira zapaljivost prostirke (mrtvog šumskog goriva) te ponašanje požara jest udio vlage, koji je izravno ovisan o meteorološkim uvjetima (temperatura, relativna vlažnost zraka, oborina, vjetar), ali i značajkama same prostirke (kapacitet vezanja vode, njena prozračnost itd.).

Udio vlage različit je za sve podhorizonte šumske prostirke i može se, ovisno o podhorizontu, mijenjati na bazi sata, tjedna, mjeseca ili čak sezone. OL-podhorizont ili listinac predstavlja površinski sloj šumske prostirke u kojemu se jasno razlikuju dijelovi biljaka (iglice, lišće, grančice, kora, češeri i sl.). Zbog male gustoće te izravnog kontakta s atmosferom OL-podhorizont ima velike i brze fluktuacije u udjelu vlage (na bazi sata), odnosno brzo se suši, lako zapali i obično gori plamtećim izgaranjem (engl. flaming combustion). Udio vlage ovog sloja (engl. fine fuel moisture content), odnosno mrtvog biljnog materijala do $6 \mathrm{~mm}$ promjera, posebno je važan čimbenik jer utječe na vjerojatnost zapaljenja, brzinu širenja, intenzitet požara i potrošnju goriva (Slijepčević i dr., 2015), zbog čega je okosnica gotovo svih modela za procjenu opasnosti od šumskih požara te modela za predikciju ponašanja i širenja šumskog požara.

U OF podhorizontu biljni ostaci su fragmentirani, umjereno razgrađeni i transformirani, djelomično ili teško prepoznatljivi, često prožeti micelijem gljiva, dok su u OH podhorizontu organski ostaci humificirani, pa se više ne raspoznaje njihova struktura. Podhorizonti OF i OH imaju veću gustoću i nisu u izravnom kontaktu s atmosferom, pa se sporije suše (Miyanishi, 2001; Van Wagner, 1987), te su uz veći kapacitet za vodu obično i znatno vlažniji od OLpodhorizonta (Banwell i dr., 2013). Zbog toga se teže zapale i gore tinjajućim izgaranjem (engl. smouldering combustion) nakon prolaska glavne plamene fronte (Keane, 2015; Miyanishi, 2001; Wilmore, 2001), iako, ukoliko su dovoljno suhi, i ovi slojevi šumske prostirke mogu biti zahvaćeni plamtećim izgaranjem.

Informacije o šumskoj prostirci se zbog navedenih svojstava tradicionalno koriste u modelima za procjenu opasnosti od šumskih požara te modelima za predikciju ponašanja i širenja šumskih požara, a u novije vrijeme i za procjenu emisija ugljika i drugih plinova, kvantificiranje zaliha ugljika te opisivanje staništa i njegove produktivnosti (Keane i dr., 2012; Sommers i dr., 2014; Weise i Wright, 2014). U globalnom ciklusu ugljika, požari imaju veliku ulogu u oslobađanju zaliha terestričkog ugljika vezanog u različitim sastavnicama kopnenih ekosustava (biomasa, šumska prostirka, tlo). Globalno gledajući, zbog požara se prosječno godišnje (1997.-2009.) u atmosferu oslobodi 2 Pg ugljika (van der
Werf i dr., 2010), što iznosi $22 \%$ u odnosu na globalnu emisiju ugljika zbog izgaranja fosilnih goriva (French i dr., 2011). Količina izravno oslobođenog ugljika u požaru jako varira i ovisi o količini i vrsti goriva, kemijskom sastavu goriva, strukturi i rasporedu goriva, meteorološkim uvjetima tijekom požara (Sommers i dr., 2014), ali i o tipu izgaranja svake komponente goriva (French i dr., 2011). Informacije o šumskoj prostirci su posebno važne za modeliranje izravnih emisija ugljika tijekom požara, jer je izgaranje ovog sloja šumskog goriva zbog opisanih svojstava jako varijabilno i predstavlja najveći izvor nesigurnosti u procjeni ukupnih emisija ugljika tijekom požara (de Groot i dr., 2009).

Kanada i SAD, kao zemlje s dugogodišnjom znanstvenom, stručnom i operativnom praksom u upravljanju šumskim požarima, imaju velike i kvalitetne baze podataka o šumskim gorivima, uključujući i prostirku. Izradom kvalitetnih regresijskih modela operativcima je omogućeno da na temelju jednostavnije mjerljivih varijabli, u ovom slučaju debljine prostirke, dođu do količine raspoloživog mrtvog goriva u šumskoj prostirci, kao jedne od teže mjerljivih varijabli, a isto tako i do maksimalno raspoloživih zaliha ugljika koje se u šumskom požaru mogu iz prostirke osloboditi u atmosferu. Uporaba regresijskih modela dobivenih sustavnim znanstvenim istraživanjima, uobičajena je praksa za određivanje količine prostirke kao funkcije njene debljine (Brown i dr., 1982; Brown i dr., 2004; Knapp i dr., 2005; Letang i de Groot, 2012; Wagtendonk i dr., 1998), a dobivene količine koriste se u uvodno navedenim modelima.

U skladu s navedenim, usmjerena su i istraživanja koja se prezentiraju u ovome radu. Glavni ciljevi su utvrditi debljine, gustoće i količine podhorizonata šumske prostirke uz pripadajuće zalihe ugljika u sastojinama alepskog bora te izraditi regresijske modele debljine i količine šumske prostirke, kao i debljine i zalihe ugljika po pothorizontima i ukupno.

\section{MATERIJAL I METODE ISTRAŽIVANJA MATERIAL AND METHODS OF RESEARCH}

Istraživanje je obavljeno na području Nacionalnog parka Mljet (slika 1) u zajednici alepskog bora i hrasta crnike ( $Q u$ erco ilicis-Pinetum halepensis Loisel 1971). S obzirom da se radi o nacionalnom parku, antropogeni utjecaj na količinu prostirke je minimalan. Osim toga, na malom području u sličnim stanišnim uvjetima mogu se naći sastojine različite starosti, što omogućuje praćenje akumulacije prostirke tijekom životnog ciklusa alepskog bora (kronosekvenca).

Uzorkovanje šumske prostirke obavljeno je krajem lipnja 2015. godine po debljinskim razredima: $0-50 \mathrm{~cm}, 100-150$ $\mathrm{cm}$ i $200-250 \mathrm{~cm}$ opsega. Sastojina 0-50 cm (AB50) obnovila se nakon požara 1972. godine, pa je starosti preko 40 godina. Sastojina 100-150 cm (AB150) prema Programu za gospodarenje šuma NP Mljet za razdoblje 2001.-2010. 


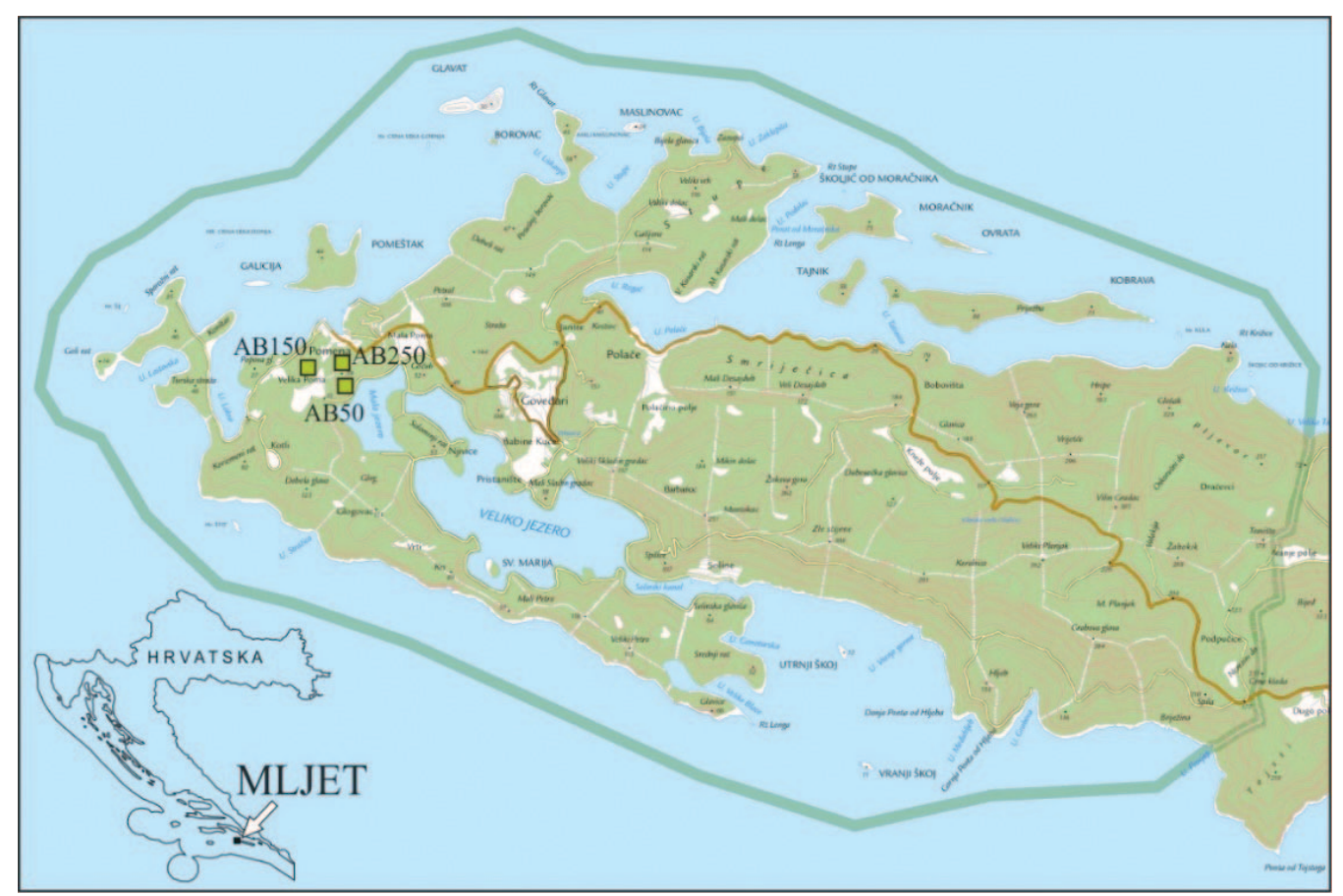

Slika 1. Područje istraživanja Figure 1 Study site

(Hrvatski šumarski institut, 2001) pripadala je VII. dobnom razredu, tako da je sada starosti između 70 i 80 godina. Unutar ovih starih sastojina pronađena su i pojedinačna stabla opsega 200-250 cm (AB250) čija je starost, na temelju saznanja djelatnika nacionalnog parka, procijenjena na 120

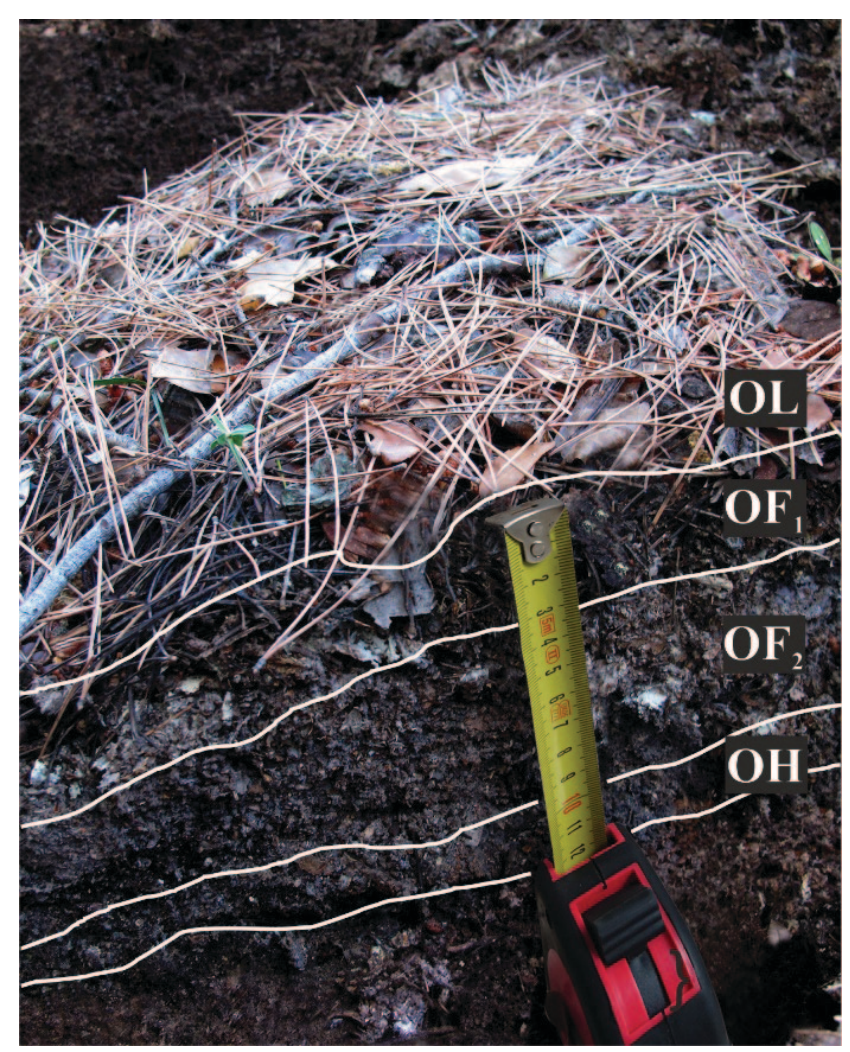

Slika 2. Podhorizonti šumske prostirke u sastojini alepskog bora $A B 250$ Figure 2 Forest floor horizons in Aleppo pine forest AB 250 godina. Prilikom izbora ploha vodilo se računa o tome da matični supstrat i tlo budu razmjerno homogeni te da nagib terena na svim plohama bude što manji, kako bi njegov utjecaj na distribuciju prostirke bio minimalan. Ispod krošanja alepskog bora odabirani su zaravnjeni mikrolokaliteti $s$ nagibom do $5^{\circ}$ (zaravni, prirodne terase) i minimalnom površinskom stjenovitosti. Matični supstrat na svim plohama činili su uslojeni vapnenci s ulošcima dolomita na kojima dominira kalkomelanosol, a tek sporadično se javlja kalkokambisol plitki.

U svakom debljinskom razredu uzeto je po 10 uzoraka prostirke s plohice dimenzija 30 x $30 \mathrm{~cm}$. Uzorkovanje je obavljeno po podhorizontima (slika 2) na sljedeći način:

- OL - posebno su izdvajane iglice alepskog bora, listovi crnike i ostalih vrsta, kao i grančice tanje od $6 \mathrm{~mm}$;

- OF - iako metodologija ne predviđa zasebno uzorkovanje, OF-pothorizont je uzorkovan $\mathrm{u}$ dva dijela. $\mathrm{OF}_{1}$, koji se nalazi ispod OL-pothorizonta, izdvojen je zbog toga što bi se prilikom požara mogao ponašati slično OL-pothorizontu, od kojega se razlikuje tamnijom bojom, neznatnom fragmentiranošću i početnim stupnjem razgradnje. $\mathrm{OF}_{2}$ nalazi se ispod $\mathrm{OF}_{1}$, a stupanj razgradnje je značajniji, pri čemu su pojedni dijelovi biljnog materijala djelomično ili slabije raspoznatljivi;

- $\mathrm{OH}$ - humificirani organski ostaci koji su od $\mathrm{OF}_{2}$ razdvajani uz pomoć sita dimenzija otvora $2 \mathrm{~mm}$, a u dodiru $\mathrm{s}$ mineralnim dijelom tla ručno izdvajani te po potrebi prosijavani. Svi uočljivi mineralni fragmenti tla odmah su odvajani. 
Tablica 1. Količina šumske prostirke (goriva) po podzhorizontima $O L, \mathrm{OF}_{1}, \mathrm{OF}_{2}$ i $\mathrm{OH}$ u sastojinama alepskog bora $A B 50, A B 150$ i $A B 250$ (N = 10 za svaki debljinski razred)

Table 1 Forest floor fuel loads in $\mathrm{OL}, \mathrm{OF}_{1}, \mathrm{OF}_{2}$ and $\mathrm{OH}$ horizons in Aleppo pine forests $\mathrm{AB} 50, \mathrm{AB} 150$ i $\mathrm{AB} 250$ ( $\mathrm{N}=10$ for each size class)

\begin{tabular}{|c|c|c|c|c|c|c|}
\hline $\begin{array}{l}\text { Sloj } \\
\text { Horizon }\end{array}$ & $\begin{array}{l}\text { Aritm. sred. } \\
\text { Mean }\end{array}$ & $\begin{array}{l}\text { Medijan } \\
\text { Median }\end{array}$ & $\begin{array}{l}\text { Minimum } \\
\text { Minimum }\end{array}$ & $\begin{array}{l}\text { Maksimum } \\
\text { Maximum }\end{array}$ & $\begin{array}{l}\text { Std. devijacija } \\
\text { Std. dev. }\end{array}$ & $\begin{array}{l}\text { Std. pogreška } \\
\text { Std. error }\end{array}$ \\
\hline \multicolumn{7}{|c|}{$\begin{array}{l}\text { Količina prostirke AB } 50\left(\mathrm{Mg} \mathrm{ha}^{-1}\right) \\
\text { Forest floor fuel load } A B 50\left(\mathrm{Mg} \mathrm{ha}^{-1}\right)\end{array}$} \\
\hline $\mathrm{OL}$ & 1,323 & 1,325 & 1,007 & 1,602 & 0,202 & 0,064 \\
\hline $\mathrm{OF}_{1}$ & 14,890 & 14,646 & 8,863 & 25,436 & 4,792 & 1,515 \\
\hline $\mathrm{OF}_{2}$ & 9,502 & 7,609 & 3,571 & 22,874 & 6,442 & 2,037 \\
\hline $\mathrm{OH}$ & 4,095 & 2,335 & 0,851 & 9,413 & 3,382 & 1,070 \\
\hline Ukupno - Total & 29,810 & 29,224 & 14,888 & 48,965 & 10,762 & 3,403 \\
\hline \multicolumn{7}{|c|}{$\begin{array}{l}\text { Količina prostirke AB } 150\left(\mathrm{Mg} \mathrm{ha}^{-1}\right) \\
\text { Forest floor fuel load AB } 150\left(\mathrm{Mg} \mathrm{ha}^{-1}\right)\end{array}$} \\
\hline $\mathrm{OL}$ & 1,690 & 1,570 & 1,060 & 2,610 & 0,516 & 0,163 \\
\hline $\mathrm{OF}_{1}$ & 18,447 & 19,047 & 8,940 & 27,798 & 5,478 & 1,732 \\
\hline $\mathrm{OF}_{2}$ & 21,743 & 20,448 & 13,783 & 36,686 & 7,993 & 2,528 \\
\hline $\mathrm{OH}$ & 11,734 & 10,880 & 5,990 & 17,826 & 4,353 & 1,376 \\
\hline Ukupno - Total & 53,613 & 58,230 & 29,903 & 70,153 & 13,921 & 4,402 \\
\hline \multicolumn{7}{|c|}{$\begin{array}{l}\text { Količina prostirke AB } 250\left(\mathrm{Mg} \mathrm{ha}^{-1}\right) \\
\text { Forest floor fuel load AB } 250\left(\mathrm{Mg} \mathrm{ha}^{-1}\right)\end{array}$} \\
\hline $\mathrm{OL}$ & 1,900 & 1,552 & 0,756 & 3,506 & 0,957 & 0,303 \\
\hline $\mathrm{OF}_{1}$ & 24,886 & 25,444 & 15,062 & 32,829 & 4,824 & 1,526 \\
\hline $\mathrm{OF}_{2}$ & 40,385 & 33,750 & 26,238 & 78,139 & 16,165 & 5,112 \\
\hline $\mathrm{OH}$ & 27,140 & 28,811 & 3,479 & 36,558 & 10,242 & 3,239 \\
\hline Ukupno - Total & 94,310 & 93,521 & 46,317 & 131,791 & 23,031 & 7,283 \\
\hline
\end{tabular}

Na svakom uzorku izmjerena je dubina pojedinog podhorizonta na sve četiri strane, a njihova prosječna vrijednost predstavljala je konačnu dubinu podhorizonta. Posebno su izdvojeni češeri i grančice iznad $6 \mathrm{~mm}$ promjera, kao i kora na površini OL (njihove mase prikazane su odvojeno). Masa suhe tvari dobivena je sušenjem uzoraka 24 sata na $100^{\circ} \mathrm{C}$, a ukoliko se radilo o većem i vlažnijem uzorku (OF, $\mathrm{OH})$, sušenje je trajalo $48 \mathrm{~h}$. Količina goriva izražena je masom suhe tvari po jedinici površine $\left(\mathrm{Mg} \mathrm{ha}^{-1}\right)^{\star}$.

Kako bi se odredila zaliha ugljika u prostirci određen je njegov udio po podhorizontima u svim kategorijama opsega alepskog bora, a dobivena srednja vrijednost pomnožena je s količinom prostirke. Uzorkovanje je obavljeno po podhorizontima $\mathrm{OL}\left(\mathrm{OL}_{\mathrm{G}} \mathrm{i} \mathrm{OL}_{\mathrm{AL}}\right.$ zasebno), OF $\left(\mathrm{OF}_{1} \mathrm{i}_{\mathrm{OF}} \mathrm{za}-\right.$ jedno) $\mathrm{iOH}$, a udio organskog ugljika ( $\mathrm{N}=15 \mathrm{za}$ svaki podhorizont) određen je suhim spaljivanjem u skladu s HRN ISO 10694:2004 normom. Masa suhog uzorka dobivena je sušenjem na $50^{\circ} \mathrm{C}$ do konstantne mase.

Količina šumske prostirke i zaliha organskog ugljika po podhorizontima obrađene su deskriptivnom statistikom. Greška tipa I (a) od 5\% smatrana je statistički značajnom (Sokkal \& Rohlf, 1995). Razlike količina prostirke i zaliha ugljika između istovrsnih podhorizonata po debljinskim ra- zredima testirane su analizom varijance, jer je bio zadovoljen uvjet homogenosti varijance. Kad je analiza varijance pokazala da postoji statistički značajna razlika, pojedinačne razlike testirane su Tukey-evim višestrukim post hoc testom (Petz i dr., 2012). Regresijskom analizom utvrđena je veza debljina prostirke i pripadajućih količina, odnosno zaliha ugljika te su dane regresijske jednadžbe. Statistička analiza podataka obavljena je u programima Excel i Statistica (StatSoft, Inc, 2007).

\section{REZULTATI ISTRAŽIVANJA}

\section{RESEARCH RESULTS}

\section{Debljina i gustoća prostirke}

Debljina šumske prostirke u sastojini alepskog bora AB50 iznosi $3,7 \pm 0,7 \mathrm{~cm}$ (aritm. sred. + std. dev.), u sastojini AB150 $6,1 \pm 1,4 \mathrm{~cm}$, a u sastojini AB250 9,0 $\pm 2,6 \mathrm{~cm}$. Za sve sastojine gotovo je jednaka debljina $\mathrm{OL} \mathrm{i} \mathrm{OF}_{1}$ pothorizonata, dok se sa starošću debljina $\mathrm{OF}_{2} \mathrm{i} \mathrm{OH}$ povećava (slika 3). Debljina $\mathrm{OF}_{2}$ povećava se sa $0,9 \pm 0,4 \mathrm{~cm}$ (AB50), na $2,2 \pm 0,5 \mathrm{~cm}$ (AB150) te $4,1 \pm 1,7 \mathrm{~cm}(\mathrm{AB} 250)$, a $\mathrm{OH}$ sa $0,4 \pm 0,3 \mathrm{~cm}$ (AB50), na 1,5 $\pm 0,7 \mathrm{~cm}(\mathrm{AB} 150)$ te $2,4 \pm 1,3 \mathrm{~cm}$ (AB250).

\footnotetext{
* Svi rezultati izraženi su u Mg ha ${ }^{-1}$ (t/ha) zbog toga što je to uobičajeno u našoj šumarskoj praksi. Međutim, u istraživanjima vezanim uz šumske požare češće se upotrebljava jedinica $\mathrm{kg} \mathrm{m}^{-2}$.
} 
Slika 3. Srednje vrijednosti debljine $(\mathrm{cm})$ podhorizonata šumske prostirke $\mathrm{OL}, \mathrm{OF}_{1}$, $\mathrm{OF}_{2}$ i OH za sastojine alepskog bora $\mathrm{AB50}$, $A B 150$ i $A B 250(N=10$ za svaki debljinski razred).

Figure 3 Average depths $(\mathrm{cm})$ of the forest floor horizons $\mathrm{OL}, \mathrm{OF}_{1}, \mathrm{OF}_{2}$ and $\mathrm{OH}$ in Aleppo pine forests $A B 50, A B 150$ and $A B 250(N=$ 10 for each size class).

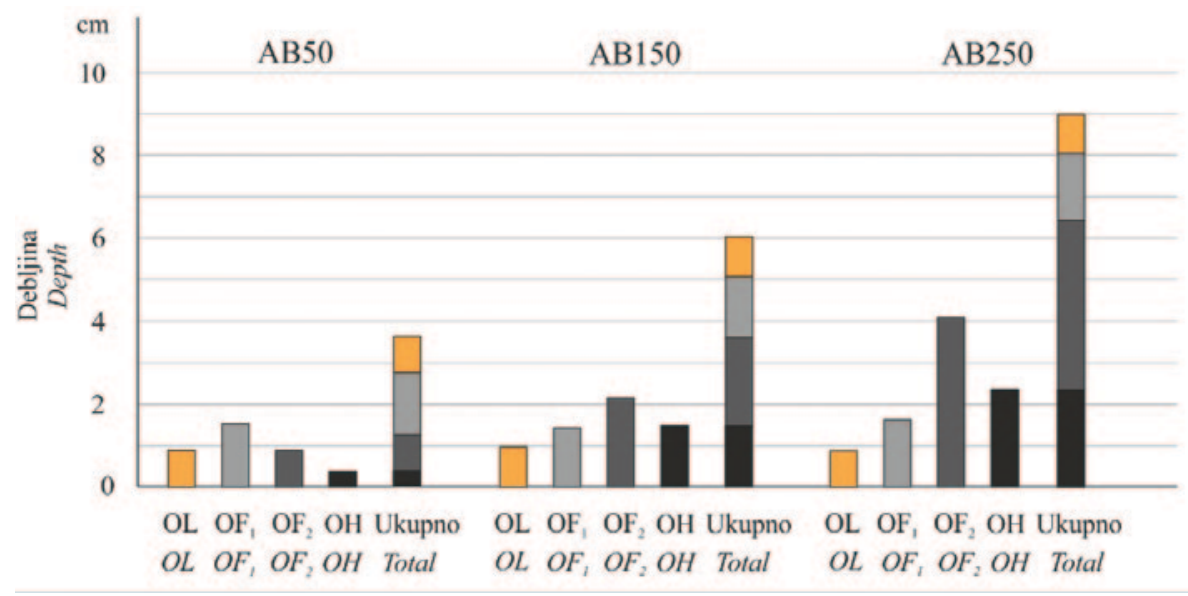

Slika 4. Srednje vrijednosti količina (Mg $\mathrm{ha}^{-1}$ ) sastavnica OL-podhorizonta: grančice promjera ispod $6 \mathrm{~mm}\left(\mathrm{OL}_{\mathrm{G}}\right)$, iglice alepskog bora $\left(\mathrm{OL}_{\mathrm{AL}}\right)$, lišće crnike $\left(\mathrm{OL}_{\mathrm{CRN}}\right)$, lišće ostalih listača $\left(\mathrm{OL}_{O L}\right)$ i ukupno $\left(\mathrm{OL}_{U K}\right)$ u sastojinama alepskog bora $A B 50, A B 150$ i $A B 250$ ( $N=10$ za svaki debljinski razred)

Figure 4 Average fuel loads $\left(\mathrm{Mg} \mathrm{ha}^{-1}\right)$ of the OL horizon by components: twigs less than 6 $\mathrm{mm}$ diameter $\left(\mathrm{OL}_{\mathrm{G}}\right)$, Aleppo pine needles $\left(\mathrm{LL}_{\mathrm{AL}}\right)$, Holm oak leaves $\left(\mathrm{OL}_{\mathrm{CRN}}\right)$, other broadleaves $\left(\mathrm{OL}_{0 L}\right)$ and total fuel load for $\left(\mathrm{OL}_{\mathrm{TOT}}\right)$ AB50, AB150 i AB250 ( $N=10$ for each size class)

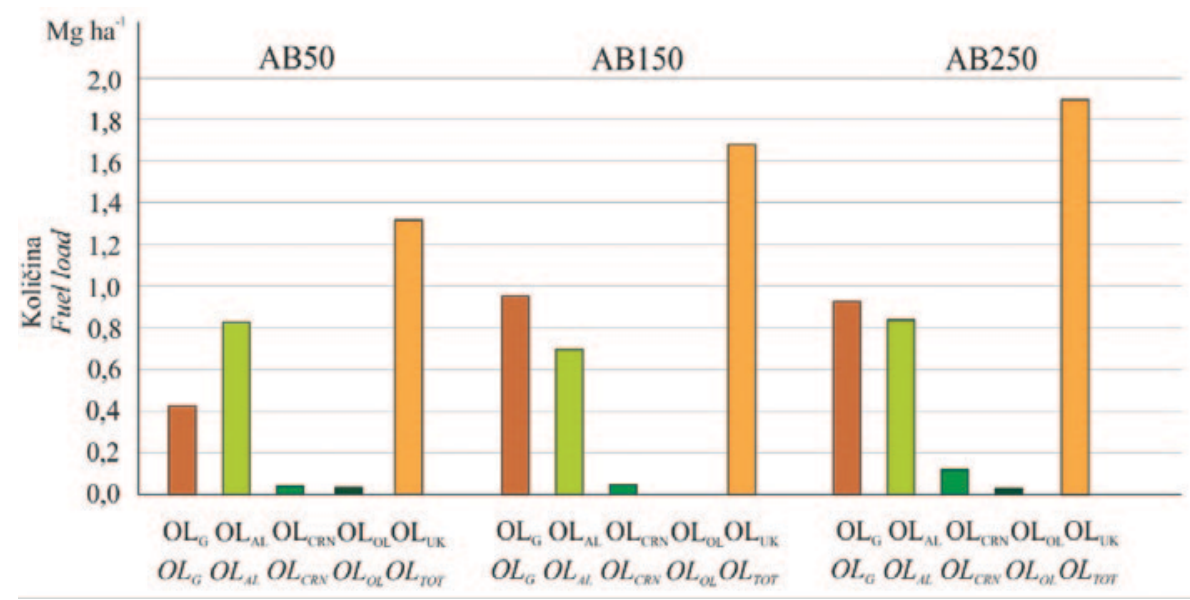

Kako nisu utvrđene statistički značajne razlike u gustoćama između istovrsnih podhorizonata različitih kategorija opsega stabala, dana je srednja vrijednost gustoća za sve uzorke $(\mathrm{N}=30)$. Gustoća OL-podhorizonta iznosi 19,5 \pm $7,9 \mathrm{~kg} \mathrm{~m}^{-3}$, OF-podhorizonta $115,0 \pm 35,1 \mathrm{~kg} \mathrm{~m}^{-3}$, a OHpodhorizonta $104,4 \pm 38,9 \mathrm{~kg} \mathrm{~m}^{-3}$.

\section{Količina prostirke}

Količina prostirke povećava se sa starošću sastojine pa za AB50 iznosi 29,8 $\mathrm{Mg} \mathrm{ha}^{-1}$, za AB150 53,6 $\mathrm{Mg} \mathrm{ha}^{-1}$, a za AB250 94,3 $\mathrm{Mg} \mathrm{ha}^{-1}$ (tablica 1).

Za OL-podhorizont nije utvrđena statistički značajna razlika između sastojina. Udio grančica $\left(\mathrm{OL}_{\mathrm{G}}\right)$ ispod $6 \mathrm{~mm}$ promjera povećava se sa starošću s $0,43 \pm 0,22 \mathrm{Mg} \mathrm{ha}^{-1}$ (AB 50), na $0,96 \pm 0,44 \mathrm{Mg} \mathrm{ha}^{-1}$ (AB 150), odnosno $0,93 \pm 0,74$ $\mathrm{Mg} \mathrm{ha}^{-1}$. Udio iglica alepskog bora je podjednak i kreće se od 0,83 $\pm 0,21 \mathrm{Mg} \mathrm{ha}^{-1}$ (AB 50), preko 0,69 $\pm 0,23 \mathrm{Mg} \mathrm{ha}^{-1}$ (AB 150) do 0,84 $\pm 0,40 \mathrm{Mg} \mathrm{ha}^{-1}$ (AB 250). Udio lišća crnike također je podjednak i kreće se od $0,04 \pm 0,06 \mathrm{Mg} \mathrm{ha}^{-1}(\mathrm{AB}$ 50), preko 0,04 $\pm 0,06 \mathrm{Mg} \mathrm{ha}^{-1}$ (AB 150) do $0,11 \pm 0,12 \mathrm{Mg}$ ha $^{-1}$ (AB 250), dok je udio listinca ostalih listača minimalan i po rezultatima ne prelazi $0,13 \mathrm{Mg} \mathrm{ha}^{-1}$. AB250 statistički se značajno razlikuje od $\mathrm{AB} 50$ i $\mathrm{AB} 150$ po većoj količini $\mathrm{OF}_{1}(\mathrm{~F}=10,100 ; \mathrm{p}<0,001)$ i $_{2}(\mathrm{~F}=19,785 ; \mathrm{p}<0,001)$, dok se po količini $\mathrm{OH}(\mathrm{F}=30,555 ; \mathrm{p}<0,001)$ sve sastojine (AB50, AB150 i AB250) statistički značajno razlikuju.

U obračunu količine OL nisu uračunate grančice iznad 6 mm promjera, kora i češeri. Prilikom uzorkovanja u sastojini $\mathrm{AB} 50$ isti nisu niti zabilježeni. Za AB150 količina češera iznosi $0,808 \pm 1,463 \mathrm{Mg} \mathrm{ha}^{-1}$, a količina grančica iznad $6 \mathrm{~mm} 0,690 \pm 1,288 \mathrm{Mg} \mathrm{ha}^{-1}$, dok za AB250 količina češera iznosi $0,351 \pm 1,022 \mathrm{Mg} \mathrm{ha}^{-1}$, grančica iznad $6 \mathrm{~mm}$ $1,421 \pm 4,492 \mathrm{Mg} \mathrm{ha}^{-1}$ i kore $0,343 \pm 1,085 \mathrm{Mg} \mathrm{ha}^{-1}$.

\section{Udio i zaliha organskog ugljika}

S obzirom da $\mathrm{OL}_{\mathrm{G}} \mathrm{i} \mathrm{OL}_{\mathrm{AL}}$ čine više od $93 \%$ mase u OL pothorizontu, u njima je određen udio organskog ugljika, kao i u OF i OH pothorizontima. Udio ugljika (aritm. sred. \pm std. dev.) $\mathrm{u} \mathrm{OL} \mathrm{G}_{\mathrm{G}}$ iznosi $50,10 \pm 0,31 \%, \mathrm{u} \mathrm{OL}_{\mathrm{AL}} 52,99 \pm 0,65$ $\%$, u OF 40,83 $\pm 4,14 \%$ i u OH $34,54 \pm 3,14 \%$ (slika 5). Ovi udjeli korišteni su prilikom izračuna zalihe ugljika u tablici 2.

Zaliha organskog ugljika povećava se sa starošću sastojine, pa za AB50 iznosi 12,1 $\mathrm{Mg} \mathrm{C} \mathrm{ha-1}^{-1}$, za AB150 21,3 Mg C $\mathrm{ha}^{-1}$, a za AB250 37,0 $\mathrm{MgC} \mathrm{ha}^{-1}$ (tablica 2). Prema zalihama ugljika za OL pothorizont nije utvrđena statistički značajna razlika između sastojina. AB250 statistički se značajno razlikuje od AB50 i AB150 po većoj zalihi ugljika 


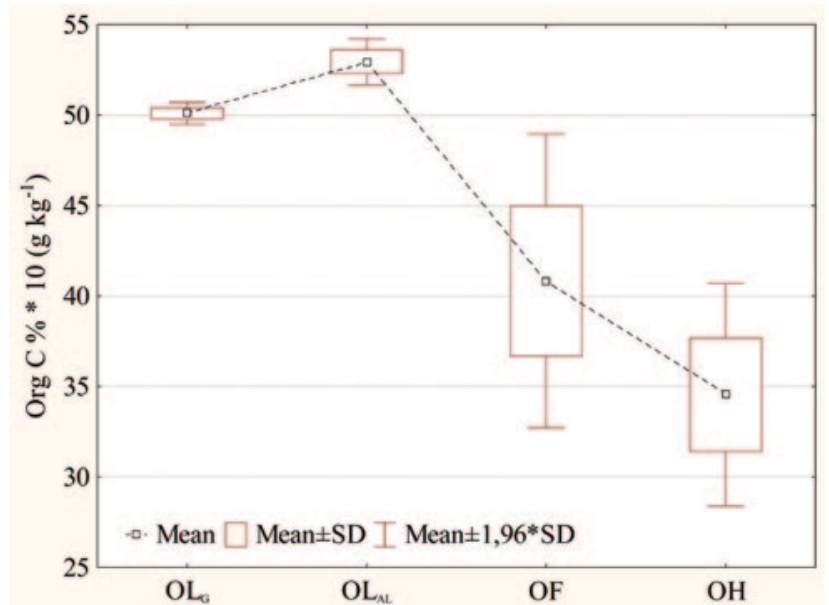

Slika 5. Udio organskog ugljika za grančice tanje od $6 \mathrm{~mm}$ promjera $\left(\mathrm{L}_{\mathrm{G}}\right)$, iglice alepskog bora $\left(\mathrm{OL}_{\mathrm{AL}}\right), \mathrm{OF} \mathrm{i} \mathrm{OH}$ podhorizonte $(\mathrm{N}=15$ za svaki podhorizont)

Figure 5 Organic carbon content in twigs less than $6 \mathrm{~mm}$ diameter $\left(\mathrm{OL}_{\mathrm{G}}\right)$, Aleppo pine needles $\left(\mathrm{OL}_{\mathrm{AL}}\right), \mathrm{OF}$ and $\mathrm{OH}$ horizons $(\mathrm{N}=15$ for each organic horizon)

$\mathrm{u} \mathrm{OF}_{1}(\mathrm{~F}=13,869 ; \mathrm{p}<0,001)$, dok se po zalihi ugljika u $\mathrm{OF}_{2}$ $(\mathrm{F}=21,324 ; \mathrm{p}<0,001)$ i OH $(\mathrm{F}=29,189 ; \mathrm{p}<0,001)$ sve sastojine (AB50, AB150 i AB250) statistički značajno razlikuju.

\section{Odnos debljine prostirke prema količini i zalihi} organskog ugljika

Regresijskom analizom utvrđena je statistički značajna veza debljina šumske prostirke s količinama prostirke i zalihama ugljika te su dani regresijski modeli za OL-pothorizont, zatim za $\mathrm{OF}_{1}, \mathrm{OF}_{2}$ i OH zajedno, kao i za ukupnu prostirku (slika 6). U tablici 3 prikazani su regresijski modeli odnosa debljine prostirke s količinom i zalihom organskog ugljika te njihova validacija.

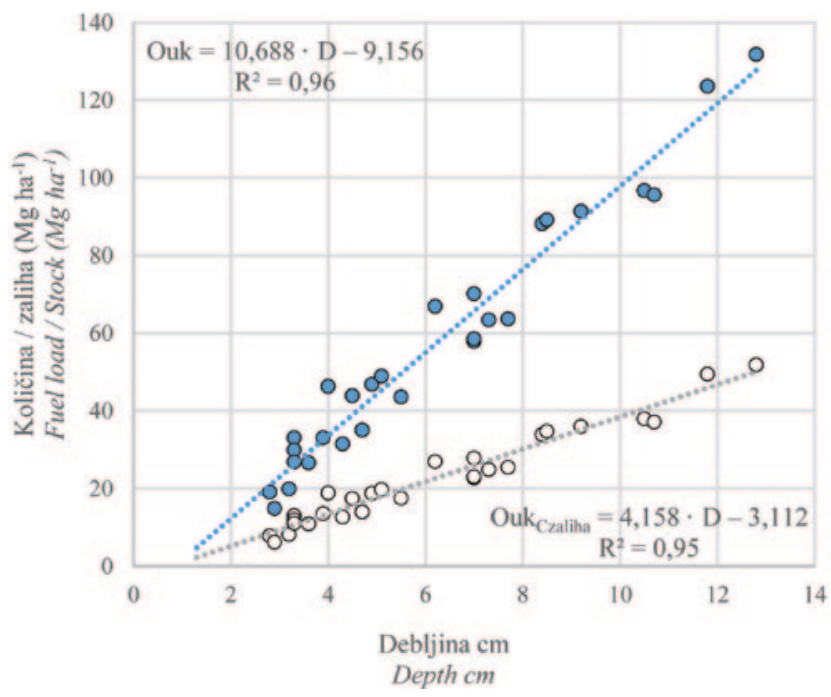

Slika 6. Regresijski modeli za procjenu ukupne količine prostirke (Ouk $=10,688 \cdot D-9,156)$ i ukupne zalihe ugljika $\left(\right.$ Ouk $_{\text {czaliha }}=4,158 \cdot D-$ 3,112 ) temeljem debljine prostirke (D). Plave točkice označavaju količine prostirke, a bijele zalihe organskog ugljika

Figure 6 Regression models for forest floor fuel loads (Ouk $=10,688 \cdot D$ $-9,156)$ and Carbon stocks (Ouk Czaliha $=4,158 \cdot D-3,112)$ as a function of forest floor depths (D). Blue marks represent a forest floor fuel loads and white marks represent Carbon stocks

Tablica 2. Zaliha organskog ugljika po pothorizontima $\mathrm{OL}, \mathrm{OF}_{1}, \mathrm{OF}_{2}$ i H u sastojinama alepskog bora $A B 50, A B 150$ i $A B 250$ (N = 10 za svaki debljinski razred)

Table 2 Carbon stocks in $\mathrm{OL}, \mathrm{OF}_{1}, \mathrm{OF}_{2}$ and $\mathrm{H}$ horizons of Aleppo pine forests $\mathrm{AB} 50, \mathrm{AB} 150$ i $\mathrm{AB} 250$ ( $\mathrm{N}=10$ for each size class)

\begin{tabular}{|c|c|c|c|c|c|c|}
\hline $\begin{array}{l}\text { Sloj } \\
\text { Horizon }\end{array}$ & $\begin{array}{l}\text { Aritm. sred. } \\
\text { Mean }\end{array}$ & $\begin{array}{l}\text { Medijan } \\
\text { Median }\end{array}$ & $\begin{array}{l}\text { Minimum } \\
\text { Minimum }\end{array}$ & $\begin{array}{l}\text { Maksimum } \\
\text { Maximum }\end{array}$ & $\begin{array}{l}\text { Std. devijacija } \\
\text { Std. dev. }\end{array}$ & $\begin{array}{l}\text { Std. pogreška } \\
\text { Std. error }\end{array}$ \\
\hline \multicolumn{7}{|c|}{$\begin{array}{l}\text { Zaliha Org. C AB } 50\left(\mathrm{Mg} \mathrm{ha}^{-1}\right) \\
\text { Carbon stock AB50 }\left(\mathrm{Mg} \mathrm{ha}^{-1}\right)\end{array}$} \\
\hline $\mathrm{OL}$ & 0,688 & 0,687 & 0,526 & 0,834 & 0,104 & 0,033 \\
\hline $\mathrm{OF}_{1}$ & 6,080 & 5,980 & 3,619 & 10,385 & 1,957 & 0,619 \\
\hline $\mathrm{OF}_{2}$ & 3,880 & 3,107 & 1,458 & 9,339 & 2,630 & 0,832 \\
\hline $\mathrm{OH}$ & 1,414 & 0,807 & 0,294 & 3,252 & 1,168 & 0,369 \\
\hline Ukupno - Total & 12,062 & 11,849 & 6,205 & 19,730 & 4,232 & 1,338 \\
\hline \multicolumn{7}{|c|}{$\begin{array}{l}\text { Zaliha Org. C AB } 150\left(\mathrm{Mg} \mathrm{ha}^{-1}\right) \\
\text { Carbon stock } A B 150\left(\mathrm{Mg} \mathrm{ha}^{-1}\right)\end{array}$} \\
\hline $\mathrm{OL}$ & 0,867 & 0,802 & 0,549 & 1,332 & 0,262 & 0,083 \\
\hline $\mathrm{OF}_{1}$ & 7,532 & 7,777 & 3,650 & 11,350 & 2,237 & 0,707 \\
\hline $\mathrm{OF}_{2}$ & 8,877 & 8,349 & 5,628 & 14,978 & 3,264 & 1,032 \\
\hline $\mathrm{OH}$ & 4,053 & 3,758 & 2,069 & 6,157 & 1,504 & 0,475 \\
\hline Ukupno - Total & 21,329 & 22,904 & 11,949 & 27,883 & 5,495 & 1,738 \\
\hline \multicolumn{7}{|c|}{$\begin{array}{l}\text { Zaliha Org. C AB } 250\left(\mathrm{Mg} \mathrm{ha}^{-1}\right) \\
\text { Carbon stock } A B 250\left(\mathrm{Mg} \mathrm{ha}^{-1}\right)\end{array}$} \\
\hline $\mathrm{OL}$ & 1,000 & 0,806 & 0,391 & 1,778 & 0,468 & 0,148 \\
\hline $\mathrm{OF}_{1}$ & 10,161 & 10,388 & 6,150 & 13,404 & 1,970 & 0,623 \\
\hline $\mathrm{OF}_{2}$ & 16,489 & 13,780 & 10,713 & 31,903 & 6,600 & 2,087 \\
\hline $\mathrm{OH}$ & 9,375 & 9,952 & 1,202 & 12,628 & 3,538 & 1,119 \\
\hline Ukupno - Total & 37,024 & 36,550 & 18,866 & 51,858 & 9,078 & 2,871 \\
\hline
\end{tabular}


Tablica 3. Regresijski modeli odnosa debljina prostirke s pripadajućim količinama prostirke i zalihama organskog ugljika. Table 3 Regression models for forest floor fuel loads and Carbon stocks as a function of forest floor depths.

\begin{tabular}{|c|c|c|c|c|c|c|c|c|}
\hline \multirow{2}{*}{$\begin{array}{l}\mathrm{Br} . \\
\text { No }\end{array}$} & \multirow{2}{*}{$\begin{array}{l}\text { Varijabla }(N=28) \\
\text { Variable }(N=28)\end{array}$} & \multirow{2}{*}{$\begin{array}{l}\text { Regresijski model } \\
\text { Regression model }\end{array}$} & \multicolumn{6}{|c|}{ Evaluacijski parametri - Evaluation parameters } \\
\hline & & & p & MBE & MAE & RMSE & $\mathrm{R}^{2}$ & $\begin{array}{l}\text { Distribucija reziduala } \\
\text { Residual distribution }\end{array}$ \\
\hline 1 & $\begin{array}{l}\text { OL količina (Mg ha-1) } \\
\text { OL Fuel Load (Mg ha-1) }\end{array}$ & $\begin{array}{l}\mathrm{OL}=1,810 \cdot \mathrm{D} \\
(\text { s.e. }=0,100)\end{array}$ & $<0.0001$ & 0,005 & 0,402 & 0,497 & 0,55 & $\begin{array}{l}\text { Nasumična } \\
\text { Random }\end{array}$ \\
\hline 2 & $\begin{array}{l}\text { OL zaliha C }(\mathrm{Mg} \mathrm{C} \mathrm{ha-1)} \\
\text { OL C stock }\left(M g C h a^{-1}\right)\end{array}$ & $\begin{array}{l}\mathrm{OL}_{\text {Czaliha }}=0,937 \cdot \mathrm{D} \\
\text { (s.e. }=0,051)\end{array}$ & $<0.0001$ & $-0,002$ & 0,212 & 0,255 & 0,53 & $\begin{array}{l}\text { Nasumična } \\
\text { Random }\end{array}$ \\
\hline 3 & $\begin{array}{l}\text { Količina OF+OH }\left(\mathrm{Mg} \mathrm{ha}^{-1}\right) \\
\text { OF + OH Fuel Load }\left(\mathrm{Mg} \mathrm{ha}^{-1}\right)\end{array}$ & $\begin{array}{l}\mathrm{OFH}=10,549 \cdot \mathrm{D} \\
(\mathrm{s} . \mathrm{e} .=0,192)\end{array}$ & $<0.0001$ & 0,331 & 5,291 & 5,970 & 0,96 & $\begin{array}{l}\text { Nasumična } \\
\text { Random }\end{array}$ \\
\hline 4 & 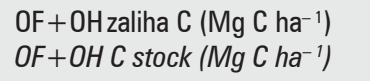 & $\begin{array}{l}\mathrm{OFH}_{\text {Czaliha }}=4,134 \cdot \mathrm{D} \\
\text { (s.e. }=0,079)\end{array}$ & $<0.0001$ & 0,058 & 2,135 & 2,439 & 0,96 & $\begin{array}{l}\text { Nasumična } \\
\text { Random }\end{array}$ \\
\hline 5 & $\begin{array}{l}\text { Količina prostirke (Mg ha-1) } \\
\text { Forest floor fuel load }\left(\mathrm{Mg} \mathrm{ha}^{-1}\right)\end{array}$ & $\begin{array}{l}\text { Ouk }=10,688 \cdot D-9,156 \\
\text { (s.e. }=0,438 ; \text { s.e. }=2,980)\end{array}$ & $<0.0001$ & 0,000 & 5,661 & 6,311 & 0,96 & $\begin{array}{l}\text { Nasumična } \\
\text { Random }\end{array}$ \\
\hline 6 & 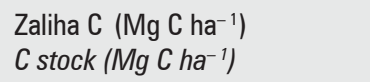 & $\begin{array}{l}\text { Ouk }_{\text {czaliha }}=4,157 \cdot \mathrm{D}-3,112 \\
\text { (s.e. }=0,177 \text {; s.e. }=1,207)\end{array}$ & $<0.0001$ & 0,000 & 2,278 & 2,556 & 0,95 & $\begin{array}{l}\text { Nasumična } \\
\text { Random }\end{array}$ \\
\hline
\end{tabular}

\section{RASPRAVA}

\section{DISCUSSION}

Prikupljanje podataka o značajkama šumskih goriva u mediteranskim ekosustavima Hrvatske započela je Bilandžija (Bilandžija, 1992; Bilandžija i Lindić, 1993). U svojim istraživanjima primjenjuje metodologiju koju daju Brown i dr. (1982). Međutim, podaci o prostirci dobiveni iz njezinih radova ne mogu se usporediti s našim rezultatima zbog nešto drukčije metodologije. Usporedba bi se eventualno mogla obaviti uvidom u izvorne podatke, gdje bi se na temelju debljina ili gustoća mogli rekonstruirati pripadajući podhorizonti šumske prostirke.

Barčić i dr. (2011) navode maksimalne količine prostirke od $37 \mathrm{Mg} \mathrm{ha}^{-1} \mathrm{u}$ kulturama alepskog bora, dok Martinović navodi 59,9 $\mathrm{Mg} \mathrm{ha}^{-1}$ (debljina 5,7 cm), upravo u sastojinama na Mljetu. Rezultati ovog istraživanja mogu se usporediti samo s rezultatima istraživanja Martinovića (2003), koji za 11 lokaliteta alepskog bora navodi nešto veće količine prostirke od ovdje prikazanih, za raspon debljina do $6 \mathrm{~cm}$. Značajno veće količine prostirke $\left(94,3 \mathrm{Mg} \mathrm{ha}^{-1}\right)$ utvrđene su ispod stabala alepskog bora opsega od 200-250 cm (tablica 1). Iako su ova stabla obuhvaćena s ciljem utvrđivanja količine prostirke starih sastojina, treba istaknuti da se radi o pojedinačnim stablima, a ne o suvisloj sastojini. Ova su istraživanja pokazala veliku varijabilnost količina šumske prostirke ukupno i po podhorizonatima za sve debljinske razrede (AB50, AB150 i AB250). Koeficijenti varijance uglavnom su u rasponu od $20-40 \%$. Slične i veće varijabilnosti količina šumske prostirke objavljene su za različite sastojine Kanade (Letang i de Groot, 2012) i gorja Stjenjaka (Keane i dr., 2012).

Godišnja akumulacija OL podhorizonta u šumama alepskog bora kreće se u širokom rasponu od 1,5 do 5,3 $\mathrm{Mg} \mathrm{ha}^{-1}$ (Arianoutsou i Radea, 2000). García-Plé i dr. (1995) temeljem dvije godine opažanja navode prosječne godišnje akumulacije OL od 2,52 i 3,44 $\mathrm{Mg} \mathrm{ha}^{-1}$, a Lado-Monserrat i dr. (2015) navode slične prosječne godišnje količine od 2,65 i 3,17 Mg ha $^{-1}$. Iglice alepskog bora dominiraju i čine od 63 do $97 \%$ udjela, najčešće 70-80\%. Dinamiku opada tijekom godine najdetaljnije su raščlanili García-Pléi dr. (1995). Oni navode da je maksimalni opad grančica i češera tijekom veljače i ožujka, cvatova u ožujku i travnju, a iglica tijekom srpnja i kolovoza. Rezultati naših istraživanja u OL pothorizontu pokazuju podjednak udio iglica alepskog bora i grančica do $6 \mathrm{~mm}$ (slika 4), a ukupna količina OL je u rasponu od 1,32 (AB50) do 1,90 $\mathrm{Mg} \mathrm{ha}^{-1}$ (AB250). S obzirom da je vrijeme uzorkovanja bilo krajem lipnja, na početku razdoblja opadanja iglica, a maksimum opada je tijekom srpnja i kolovoza, može se očekivati da bi se količina OL barem udvostručila, a udio iglica značajnije poveća.

Za svaki je pothorizont zasebno određen udio ugljika, kako bi se što preciznije mogla procijeniti njegova zaliha (De Vos i Cools, 2011). Ovi su podaci ključni za modeliranje izravnih emisija ugljika tijekom šumskih požara, jer šumska prostirka predstavlja značajan izvor emisija, a ovisno o izgorenoj količini i stupnju izgaranja, i najveći izvor nesigurnosti u procjeni ukupnih emisija ugljika tijekom požara. Udio organskog ugljika u iglicama alepskog bora u ovom radu od 529,9 $\mathrm{g} \mathrm{kg}^{-1}(52,99 \%)$ podudara se s udjelom organskog ugljika od 536,1 $\mathrm{g} \mathrm{kg}^{-1}$ kojeg navode Lado-Monserrat i dr. (2015). Koeficijenti varijance za udio ugljika u iglicama i grančicama do $6 \mathrm{~mm}$ (homogeni materijal) su niski i iznose $1,3 \%$, odnosno $0,6 \%$, dok su koeficijenti varijance za OF i $\mathrm{OH}$ očekivano viši i iznose $10,1 \%$, odnosno $9,1 \%$, što je i logično s obzirom na heterogeni sastav i različit stupanj dekompozicije. Udio organskog ugljika po svim podhorizontima šumske prostirke alepskog bora nešto je veći od prosječnih vrijednosti koje za šumsku prostirku daju De Vos i Cools (2011), dok je u odnosu na udio ugljika kojeg 
za četinjače daju Schulp i dr. (2008) ta razlika još izraženija. Ukupna zaliha ugljika u šumskoj prostirci alepskog bora povećava se sa starošću sastojine (tablica 2). Zalihe ugljika od 21,4 $\pm 5,5 \mathrm{Mg} \mathrm{C} \mathrm{ha}^{-1} \mathrm{u}$ sastojinama AB150 (starosti 7080 godina) u skladu su sa srednjim vrijednostima zaliha ugljika koje za šumsku prostirku europskih šuma navode De Vos i dr. (2012), a ona iznosi 21-23 $\mathrm{Mg} \mathrm{C} \mathrm{ha}^{-1}$. De Vos i Cools (2011) također navode da se zaliha ugljika u području Mediterana kreće u rasponu od $5-25 \mathrm{Mg} \mathrm{C}_{\text {ha }}{ }^{-1}$. Zaliha organskog uglijka u šumskoj prostirci starih šuma za umjereno topla, suha područja u rasponu je od 17,3 do 21,1 Mg C ha-1 (Penman i dr., 2003).

Regresijskim modelima definirana je povezanost debljine šumske prostirke i njene količine te zalihe ugljika. S obzirom da su razlike u gustoćama između $\mathrm{OL}$ te $\mathrm{OF}+\mathrm{OH}$ pothorizonata velike, najbolje je koristiti zasebne regresijske modele za OL (tablica 3, modeli 1 i 2) i OF+OH (tablica 3, modeli 3 i 4) prilikom izračuna količine prostirke i zalihe ugljika, pa ih na kraju sumirati. Moguće je koristiti i regresijski model za izračun ukupne količine prostirke i ukupne zalihe ugljika u prostirci (tablica 3, modeli 5 i 6), ali tek za prostirke kod kojih je $\mathrm{OF}+\mathrm{OH}$ deblji od $1 \mathrm{~cm}$, odnosno kada je ukupna debljina prostirke iznad $2,5 \mathrm{~cm}$. Primjenjivost regresijskih modela za ostale zajednice, kao i kulture alepskog bora, treba provjeriti.

\section{ZAKLJUČCI}

\section{CONCLUSIONS}

Iako se s gledišta šumskih požara prostirka promatra kao potencijalno gorivo, ne smije se zanemariti njena uloga i značaj u izmjeni tvari i energije, poglavito uglijka, u kontekstu aktualnih globalnih klimatskih promjena. Iz dobivenih rezultata vidljivo je da sastojine alepskog bora vežu značajne količine ugljika u svojoj prostirci, no uvjeti i zakonitosti nisu još dovoljno proučeni. U prilog tome govore značajno veće debljine i količine šumske prostirke u sastojinama alepskog bora od onih do sada poznatih, pa je tako ispod stabala opsega 200-250 cm utvrđena srednja debljina prostirke od 9,0 $\mathrm{cm}$ i procijenjena količina od $94,3 \mathrm{Mg} \mathrm{ha}^{-1}$ sa zalihom uglijika od $37 \mathrm{Mg} \mathrm{C} \mathrm{ha-1}$. To upućuje na potrebu sustavnih istraživanja i upotpunjavanje dosadašnjih spoznaja.

Regresijskom analizom definirana je povezanost debljine šumske prostirke i njene količine, odnosno zalihe organskog ugljika te su dani regresijski modeli. Rezultati ovog istraživanja imaju praktičnu vrijednost u jednostavnijem kvantificiranju količina goriva i zaliha ugljika. Ove se informacije mogu koristiti u modelima za procjenu opasnosti od šumskih požara te modelima za predikciju ponašanja i širenja šumskih požara, za modeliranje izravnih emisija ugljika tijekom požara te kvantificiranje zaliha ugljika. Inventarizacija šumskih goriva predstavlja osnovu za parametrizaciju i operativnu primjenu navedenih modela u Hrvatskoj.

\section{LITERATURA}

\section{REFERENCES}

- Arianoutsou, M., Radea, C., 2000. Litter production and decomposition in Pinus halepensis forests. In: Neeman, G., Trabaud, L. (Eds.), Ecology, Biogeography and Management of Pinus halepensis and P. brutia Forest Ecosystems in the Mediterranean Basin. Backhuys Publishers, Leiden, The Netherlands, pp. 183190.

- Banwell, E.M., Varner, J.M., Knapp, E.E., Van Kirk, R.W., 2013. Spatial, seasonal, and diel forest floor moisture dynamics in Jeffrey pine-white fir forests of the Lake Tahoe Basin, USA. For. Ecol. Manage. 305, 11-20.

- Barčić D., Ž. Španjol, R. Rosavec, 2011: Čimbenici utjecaja šumske prostirke na požare u šumskim ekosustavima, Vatrogastvo I upravljanje požarima, Vol. I, No. 1.

- Bilandžija, J., 1992: Prorodno opterećenje sastojina alepskog, primorskog i crnog bora šumskim gorivima, Radovi, Vol. 27, Br.2, 105-113, Jastrebarsko.

- Bilandžija, J., V. Lindić, 1993: Utjecaj strukture šumskog goriva na vjerojatnost pojave i razvoj požara u sastojinama alepskog bora (Influence of forest fuel structure on the fire probability and behaviour in Aleppo pine stands), Radovi, Vol. 28, Br. 1-2, 215-224, Jastrebarsko.

- Brown, J. K., Oberheu, R. D. \& Johnston, C. M., 1982: Handbook for Inventorying Surface Fuels and Biomass in the Interior West. General Technical Report INT - 129. Ogden, Utah: USDA Forest Service, Intermountain Forest and Range Experiment Station.

- Brown, S., D. Shoch, T. Pearson, M. Delaney, 2004. Methods for Measuring and Monitoring Forestry Carbon Projects in California. Winrock International, for the California Energy Commission, PIER Energy-Related Environmental Research. 50004-072F.

- de Groot, W. J., J. M. Pritchard, T. J. Lynham, 2009: Forest floor fuel consumtion and carbon emissions in Canadian boreal forest fires, Can. J. For. Res. 39, p 367-382.

- De Vos B., N. Cools, 2011: Forest floor and mineral SOC stocks in European forests: results from the 2004-2008 BioSoil survey, http://www.wsl.ch/fe/boden/projekte/cost-action/barcelona/ DeVoos. pdf.

- De Vos, B., N. Cools, H. Ilvesniemi, L. Vesterdal, E. Vanguelova, S. Carnicelli, 2012: Forest floor and mineral soil organic carbon stock in European forests: results from the 2004-2008 BioSoil survey, Monitoring European Forests, Detecting and Understanding changes, Abstracts of the ICP Forests Conference 2012, Warsaw, Poland.

- FAO, 2006: Guidelines for soil description, Fourth edition, Rome.

- French, N.H.F., W. J. de Groot, L.K. Jenkins, B.M. Rogers, E. Alvarado, B. Amiro, B. de Jong, S. Goetz, E. Hoy, E. Hyer, R. Keane, B. E. Law, D. McKenzie, S.G. McNulty, R. Ottmar, D.R. Pérez-Salicrup, J. Randerson, K.M. Robertson, M.Turetsky, 2011: Model comparisons for estimating carbon emissions from North American wildland fire, J. Geophys. Res., 116, G00K05, doi:10.1029/2010JG001469.

- García-Plé, C., P. Vanrell, M. Morey, 1995: Litter fall and decomposition in a Pinus halepensis forest on Mallorca, Journal of Vegetation Science 6, 17-22, IAVS, Opulus Press Uppsala. 
- Hrvatski šumarski institut, 2001: Program za gospodarenje šumama Nacionalnog parka Mljet, za razdoblje od 1.1.2001. do 31.12.2010., Odjel za uređivanje šuma i šumarsku ekonomiku Šumarskog instituta, Jastrebarsko, djelatnici poduzeća "Hrvatske šume” d.o.o., Uprave šuma Podružnica Delnice, Odjela za uređivanje šuma.

- Keane, R. E., K. Gray, V. Bacciu, 2012: Spatial variability of wildland fuel characteristics in northern Rocky Mountain ecosystems, Res. Pap. RMRS-RP-98, Fort Collins, CO: U.S. Department of Agriculture, Forest Service, Rocky Mountain Research Station, 56 p.

- Keane, R.E., 2015. Wildland fuel fundamentals and applications, Springer (eBook), $191 \mathrm{p}$.

- Knapp, E. E., J. E. Keeley, E. A. Ballenger, T. J. Brennan, 2005: Fuel reduction and coarse woody debris dynamics with early season and late season prescribed fire in a Sierra Nevada mixed conifer forest, Forest Ecology and Management 208, p 383-397.

- Lado-Monserrat, L., A. Lidón, I. Bautista, 2015: Litterfall, litter decomposition and associated nutrient fluxes in Pinus halepensis: influence of tree removal intensity in a Mediterranean forest, European Journal of Forest Research 134: 833-844, Springer-Verlag Berlin Heidelberg.

- Letang, D. L., W. J. de Groot, 2012: Forest floor depths and fuel loads in upland Canadian forests, Canadian Journal of Forest Research 42: 1551-1565, NRS Research Press.

- Martinović, J., 2003. Gospodarenje šumskim tlima u Hrvatskoj. Šumarski institut, Jastrebarsko; „Hrvatske šume“ d.o.o., Zagreb, $525 \mathrm{p}$.

- Miyanishi, K., 2001. Duff consumption. In: Johnson, E.A., Miyanishi, K. (Eds), Forest Fires: Behavior and Ecological Effects. New York, NY: Academic Press, pp. 437-475.

- Penman, J., M. Gytarsky, T. Hiraishi, T. Krug, D. Kruger, R. Pipatti, L. Buendia, K. Miwa, T. Ngara, K. Tanabe, F. Wagner, 2003: Good Practice Guidance for Land-Use Change and Forestry, The International Panel on Climate Change (IPCC).

- Petz, B., V. Kolesarić, D. Ivanec, 2012: Petzova statistika - Osnovne statističke metode za nematematičare, Naklada Slap, 680 p.

- Schulp, C. J. E., G-J. Nabuurs, P. H. Verburg, R. W. de Waal, 2008: Effect of tree species on carbon stocks in forest floor and min- eral soil and implications for soil carbon inventories, Forest Ecology and Management 256, 482-490.

- Sokkal, R. R., F. J. Rohlf, 1995: Biometry: The principles and practice of statistics in biological research. 3rd ed. W. H. Freeman, New York, 887 p.

- Slijepčević, A., W.R. Anderson, S. Mathews, D.H. Anderson, 2015: Evaluating models to predict daily fine fuel moisture content in eucalypt forest, Forest Ecology and Management 335, 261-269.

- Sommers, W.T., Loehman, R.A., Hardy, C.C., 2014. Wildland fire emissions, carbon, and climate: Science overview and knowledge needs. For. Ecol. Manage. 317, 1-8.

- StatSoft, Inc. (2007). STATISTICA (data analysis software system), version 8.0. www.statsoft.com.

- van der Werf, G.R., J.T. Randerson, L. Giglio, G.J. Collatz, M. Mu, P.S. Kasibhatla, D.C. Morton, R.S. DeFries, Y. Jin, and T.T. van Leeuwen, 2010: Global fire emissions and the contribution of deforestation, savanna, forest, agricultural, and peat fires (1997-2009), Atmos. Chem. Phys., 10, 11707-11735, doi:10.5194/acp-10-11707-2010.

- Van Wagner, C.E., 1987. Development and Structure of the Canadian Forest Fire Weather Index System. Technical Report No. 35. Canadian Forestry Service, Chalk River, Ontario, Canada.

- Wagtendonk, J. W., J. M. Benedict, W. M. Sydoriak, 1998: Fuel Bed Characteristics of Sierra Nevada Conifers, The Western Journal of Applied Forestry, Vol. 13, No 3, pp 73-84.

- Weise, D.R., Wright, C.S., 2014. Wildland fire emissions, carbon, and climate: Characterizing wildland fuels. For. Ecol. Manage. $317,26-40$.

- Wilmore, B., 2001. Duff moisture dynamics in black spruce feather moss stands and their relation to the Canadian forest fire danger rating system. M.S. Thesis, University of Alaska, Fairbanks, USA.

- Zanella, A., Jabiol, B., Ponge, J.F., Sartori, G., De Waal, R., Van Delft, B., Graefe, U., Cools, N., Kazensteiner, K., Hager, H., English, M., Breths, A., Broll, G., Gobat, J.M., Brun, J.J., Milbert, G., Kolb, E., Wolf, U., Frizzera, F., Galvan, P., Kolli, R., Baritz, R., Kemmers, R., Vacca, A., Serra, G., Banas, D., Garlato, A., Chersich, S., Klimo, E., Langohr, R., 2011: European humus forms Reference Base, p 56.

\section{Summary}

From the aspect of forest fires, the forest floor is considered a potential fuel: however, in the context of current global climate change it plays an exceptionally important role in the exchange of matter and energy and of carbon in particular. For this reason, forest floor data are traditionally used in forest fire danger rating and in fire behavior and spread models. More recently they have also been used to estimate emissions of carbon and other gasses and to gasses and to quantify carbon stocks. The main objectives of this study are to a) determine the depth, bulk density and fuel load for each forest floor horizon with the associated carbon stock in Aleppo pine stands and b) develop regression models that relate forest floor depth to forest floor fuel load and forest floor depth to forest floor carbon stock, for horizons and for the entire forest floor. Forest floor sampling was carried out in Aleppo pine stands situated in Mljet National Park, per 0-50 cm, 100-150 cm and 200-250 cm circumference classes. Each forest floor horizon was sampled separately, and fuel load and organic carbon content were determined for each horizon. Our results suggest that Aleppo pine stands contain significant carbon stocks in the forest floor, but relations and processes that influence these stocks have not been sufficiently studied. This is supported by significantly greater forest floor depths and fuel loads in Aleppo pine stands than previously reported. Thus, the mean depth of forest floor of $9.0 \mathrm{~cm}$, fuel load of $94.3 \mathrm{Mg} \mathrm{ha}^{-1}$, and carbon stock of $37 \mathrm{Mg}$ 
$\mathrm{C} \mathrm{ha}^{-1}$ were determined under trees with a 200-250 cm circumference class. Regression analysis revealed a statistically significant relationship between depth and fuel load and between depth and carbon stock. Regression models were given for the $\mathrm{OL}$ horizon, the $\mathrm{OF}_{1}, \mathrm{OF}_{2}$ and $\mathrm{OH}$ horizons, as well as for the entire forest floor. Our results have practical value as they will allow reliable quantifications of forest floor fuel loads and carbon stocks in Aleppo pine stands by using easily measurable fuel characteristic, which can then be applied in the aforementioned models. The forest fuel inventory provides the basis for parameterization and operational use of a number of forest resource management applications in Croatia.

KEY WORDS: Aleppo pine, forest floor, fuel load, carbon stocks 